\title{
PROJETOS E IMOBILIDADE(S): SORVETEIROS ÍTALO-BRASILEIROS DIANTE DA COVID-19
}

\author{
Projects and immobility(ies): \\ Italian-Brazilian ice cream makers in sight of Covid-19
}

Diane Portugueis*

Neste relato reflexivo apresentamos desdobramentos da pesquisa de doutorado (Portugueis, 2018), que envolveu a compreensão do estabelecimento da rede migratória de ítalo-brasileiros oriundos de Urussanga-SC para a Alemanha, onde exercem o trabalho de fabricantes de sorvete e atendentes em sorveterias. Buscou-se também observar a repercussão desta migração de trabalho no campo objetivo e subjetivo das vivências dos sujeitos.

A organização dessa rede é atravessada por políticas de identidade (Ciampa, 2002) que estimulam o culto à italianidade, fortemente expressada pela requisição do passaporte italiano e pela busca por sucesso e ascensão social na Alemanha, atrelada ao trabalho em sorveterias cujos proprietários são italianos. Nesse contexto, o objetivo é o retorno ao Brasil com a casa própria conquistada. Os proprietários destes estabelecimentos, por sua vez, estimulam o recrutamento específico de ítalobrasileiros com acesso ao passaporte italiano, especialmente aqueles provenientes do Município de Urussanga, no Sul de Santa Catarina, dado o acordo gemellaggio ${ }^{1}$ firmado na região, a partir do resgate das relações com os italianos da região de Longarone/Belluno, seus principais colonizadores. Estruturada nos anos 1990, esta rede migratória vem se consolidando, gerando relevantes mudanças na cidade, assim como nas organizações políticas e familiares; além de se tornar um meio de vida a partir do qual projetos pessoais são constituídos visando a migração para a Alemanha como meio de vida.

Em nossas pesquisas (Portugueis, 2016, 2018, 2020), verificamos que o modo como esta migração se organiza permite em geral que os sujeitos realizem seus planos e conquistas materiais, traduzidos na obtenção de bens em suas cidades de origem. Entretanto, não se consolida o retorno e fixação em suas moradias no Brasil

Pesquisadora no Núcleo de Estudos e Pesquisas em Identidade-Metamorfose (NEPIM), vinculado ao Grupo Interdisciplinar de Pesquisa sobre Identidade Humana do CNPQ. São Paulo, SP, Brasil. E-mail: dportugueis@gmail.com. Orcid: https://orcid.org/0000-0002-8347-2761.

1 Acordo que estabelece a duas cidades o status de cidades-irmãs, conferindo a elaboração de projetos em colaboração, cooperação política, econômica e cultural. Disponível em: < http:// www.veranopolis.rs.gov.br/cidade/17/gemellaggio >. Acesso em: 04.01.2021. 
como almejam, assim a vida nos entrelugares e a translocalidade são mantidas sem data para finalizar. Deste modo, estrutura-se uma condição que entendemos por liminar (Turner, 2013), que acarreta considerável sofrimento psicológico tanto para os sujeitos envolvidos diretamente na migração, como também para as famílias que ficam no Brasil. Observa-se que Urussanga permanece esvaziada na maior parte do ano, e o maior movimento geralmente ocorre durante a estadia dos migrantes, que retornam anualmente nos meses de férias. Estes, quando retomam seus trabalhos, deixam seus filhos aos cuidados de avós, irmãos adolescentes ou vizinhos, razão que leva a cidade a se tornar, além de esvaziada, um lugar de crianças e velhos que vivem no aguardo do retorno definitivo dos sorveteiros (Portugueis, 2018).

No entremeio desta dinâmica migratória estabelecida, consolidada e funcional, os migrantes ítalo-brasileiros são surpreendidos pela pandemia da Covid-19, o que demanda uma reconfiguração rápida de seus planos e até mesmo de seus projetos de vida (Portugueis, 2020a). Com o advento da pandemia, essa migração, orientada pelo retorno anual ao Brasil e pelo investimento na aquisição de bens imobiliários, demonstrou que não mais se seguiria como vinha acontecendo desde os anos 1990, sem maiores dificuldades de execução. A "estabilidade" vislumbrada por este modelo migratório, a consolidação das redes e a dinâmica de trabalho fez e faz com que esta prática se dissemine alcançando números consideráveis de jovens interessados. Apesar da crise política e sanitária atrelada à pandemia estudos mostram que a adesão dos jovens tende a aumentar (Portugueis, 2020b). Ainda assim, os rumos dessa dinâmica não são previsíveis.

Com a pandemia do novo coronavírus, os planos dos sorveteiros ítalobrasileiros precisaram ser alterados abruptamente. Em geral, em meados de fevereiro, eles deixam o Brasil, onde passam férias, para iniciarem a vendas de sorvetes na Alemanha. A temporada inicia-se entre o fim de fevereiro e março e continua até meados de outubro, quando os trabalhadores retornam para o Brasil. No entanto, em 2020, esses migrantes foram surpreendidos pelo avanço do vírus e pela rápida reação alemã. No mês março de 2020 foi instaurado um bloqueio no país, também denominado lockdown, em inglês, com regras e vigilância rigorosas². Segundo os sorveteiros, o funcionamento do setor gastronômico era incerto. Além disso, mesmo com a possibilidade de entregas delivery, a venda de sorvetes foi consideravelmente prejudicada pelas características próprias do produto, tais como as dificuldades de transporte e a interação social atrelada a esta prática; afinal, uma das razões por traz do consumo de sorvete é a comemoração da chegada da primavera e do verão na Alemanha, assim as sorveterias são locais de grande aglomeração (Portugueis, 2020a).

Nos relatos coletados no período estabelecido do lockdown, observamos grande sofrimento e incertezas por parte dos entrevistados. A maioria de nossos

2 Disponível em: <https://exame.com/mundo/alemanha-tem-muitos-casos-de-coronavirus-maspoucas-mortes-por-que/>. Acesso em: 17.08.2020. 
10 interlocutores passava por sua primeira experiência na sorveteria e não tinha segurança sobre a continuidade em seus postos de trabalho quando da reabertura do comércio, e sequer vislumbravam quando isto ocorreria. Outro ponto que chamou nossa atenção, foi a condição de extrema vulnerabilidade despontada. Os sorveteiros moravam em seus locais de trabalho e não podiam predizer até quando os empregadores os manteriam "comendo e morando de graça", uma vez que tal acordo é costumeiramente mantido enquanto estão trabalhando. Sem trabalho, os entrevistados não receberam salário quando as sorveterias permaneceram fechadas, tampouco auxílio emergencial e não sabiam até quando tal situação se sustentaria (Portugueis, 2020a).

Ressalta-se que, apesar de todos os entrevistados viverem legalmente documentados, alguns thes tiveram negados o acesso a direitos como assistência à saúde e auxílio emergencial do governo alemão. Essa situação é contrária ao que muitos sorveteiros buscam quando optam por investir altas somas de dinheiro e esforço na aquisição da cidadania italiana, que é parte de um projeto simbólico de retorno às origens (Costa, Zanini, 2019) e, sobretudo, dá acesso a direitos enquanto cidadãos europeus dada sua inserção na comunidade europeia.

Nos relatos obtidos, encontramos sujeitos vivendo, na prática, como extracomunitários ou não nacionais (Costa, Zanini, 2019), no modo como foram tratados no dia a dia e também na forma como se estruturaram relações de subjugo com os patrões. Os depoimentos mostraram o desconhecimento de direitos trabalhistas; em muitos casos, o contrato de trabalho era estipulado extraoficialmente, na forma de "contratos de boca". A rapidez com que o vírus se espalhou e a rápida reação do governo alemão na implementação de medidas de contenção também foram complicadores. Segundo os relatos, esta foi a razão para que alguns patrões não tenham organizado os registros de seus funcionários, "deixando para depois da pandemia". Naquele momento, os ítalo-brasileiros trabalhadores em sorveterias viram-se atrelados a uma condição de subordinação e incerteza, prejudicados também pelo desconhecimento da língua alemã, pelas burocracias do país e pelo funcionamento do próprio mercado de trabalho. Definitivamente, não encontraram o que esperavam: a migração "fácil" propagada em sua cidade, que atrela a ideia de posse do passaporte italiano a de trabalho garantido.

Durante o período da quarentena, os sujeitos entrevistados permaneceram sem salário, sem plano de saúde e sem a certeza de permanência nos alojamentos, caso os patrões resolvessem que não seria mais possível mantê-los. Ressaltamos que estes fatores foram os pontos centrais das entrevistas, sobrepondo-se ao medo do contágio pelo coronavírus.

\section{Imobilidade(s)}

Em outra situação investigada, salientamos uma dificuldade não vislumbrada, que remete também a uma condição de mudança de projetos e imobilidade, 
mesmo em posse do vermelhinho ${ }^{3}$. Relataremos o ocorrido com Flavinho, um de nossos colaboradores desde 2015, da pesquisa de doutorado (Portugueis, 2018). Mantivemos contato com ele e este ano fomos surpreendidos com seu pedido de ajuda. Tratava-se de um e-mail que deveríamos elaborar para a polícia migratória do aeroporto de Frankfurt. Para que entendamos o contexto desta solicitação é necessário retomarmos brevemente sua história.

Flavinho, quando nos concedeu entrevista para o doutorado, já trabalhava no ramo de sorveterias na Alemanha há cerca de seis anos. Possuía uma casa construída em Santa Catarina e alguma reserva financeira. Quando o conhecemos, relatou ter planos, juntamente com sua esposa, de trabalhar na sorveteria ainda até o ano de 2018 para que, então, em posse de maior reserva financeira e um carro, o casal voltasse definitivamente para o Brasil para iniciar outros projetos, como ter filhos.

Nosso último contato foi em meados de 2018. Naquele ano, o casal havia retornado para o Brasil e, a despeito de terem encontrado trabalho com baixa remuneração, mantinham o firme propósito da permanência no país, sem mais vivência entre lugares. Posteriormente, soubemos que as coisas não iam como esperavam. O salário de ambos não era suficiente para os gastos mensais e a manutenção da casa, o que fazia com que fosse necessário recorrer à reserva financeira obtida na Alemanha. Ainda assim, o plano de permanência se mantinha.

Em julho de 2020, recebemos o pedido de ajuda mencionado. O e-mail que deveríamos escrever versaria sobre as prerrogativas de entrada na Alemanha de residentes no Brasil com passaporte italiano e com contrato de trabalho na Europa. A mensagem seria escrita ainda no mesmo dia em que fomos contatados. Flavinho e sua esposa já tinham passagem marcada para a próxima semana com destino a Frankfurt, rumo a sorveteria alemã na qual trabalharam.

A reabertura gradual do comércio na Alemanha se deu em meados do mês de maio e em julho, durante o alto verão europeu, muitos consumidores já viviam a total flexibilização das normas de contenção da pandemia, e as sorveterias voltaram a ser bastante frequentadas. Dessa forma, a necessidade de contingente de trabalho (recursos humanos) voltou a aumentar e muitos ítalo-brasileiros que conseguiram retornar ao Brasil durante a quarentena foram chamados de volta, mesmo aqueles que tinham decidido permanecer em suas residências foram convidados a retomar o trabalho na Alemanha com bons salários. Os donos de sorveterias tinham pressa em reaver o dinheiro não ganho durante o tempo em quarentena e os ítalo-brasileiros, sem boas perspectivas de emprego no Brasil, não recusariam tal oferta.

Flavinho e sua esposa foram prontamente alarmados pela ideia do retorno, com a certeza da compensação financeira que não tinham em seu país. Rapidamente, após o convite do ex-patrão, os altos índices de mortes pela Covid-19 e a indicação de precaução em longas viagens de avião, não foram impeditivos

3 Como é carinhosamente apelidado o passaporte italiano (Costa, Zanini, 2019). 
para que rapidamente deixassem seus empregos e arrumassem as malas. Afinal, com o documento italiano em mãos, não haveria problemas de entrada na Europa e o e-mail para a polícia migratória tratava-se de mera formalidade/precaução. Flavinho pretendia tê-lo em mãos caso lhe fosse perguntado algo referente ao tempo residindo no Brasil sem retorno à Alemanha, por exemplo. Como colocamos, a passagem já estava comprada e não havia o que temer.

Após o rápido contato de Flavinho, a urgência do e-mail e nosso estranhamento sobre a decisão do retorno se dar tão rapidamente em meio à pandemia e após anos de planejamento para o retorno ao Brasil, recebemos a resposta do oficial da polícia: o passaporte italiano não era garantia de entrada no país! Era necessário que os sujeitos já possuíssem residência registrada na Alemanha ou uma permissão especial de entrada ${ }^{4}$. O ponto principal deste escrito foi o destaque para a recém atingida marca de um milhão de infectados no Brasil e a não necessidade/urgência de se receber pessoas vindas deste país no momento de curva ascendente de casos confirmados de coronavírus. A origem do passaporte pouco importava, e no caso particular de Flavinho, a indicação expressa era a de não embarcar.

Essa informação foi recebida com descrença por nosso interlocutor. Afinal, tinha os documentos italianos, podia atestar a posse de um contrato de trabalho, teria moradia garantida e tinha ainda alguns amigos na mesma situação que haviam embarcado semanas antes sem impedimentos. Flavinho nos pediu várias vezes para reescrever e reenviar o e-mail, argumentar com a polícia, explicar a situação. Entretanto, com a imprevisibilidade do vírus e das novas políticas de permanência no país, não havia argumento. A hipótese de Flavinho foi a de que seus amigos entraram no país ainda antes do Brasil ter alcançado a marca de um milhão de infectados e a Alemanha teria, então, mudado abruptamente as regras de entrada para pessoas vindas deste país. Flavinho buscava compreender sua má sorte, por que com ele?

Mesmo com todos os indicativos para que permanecesse em Santa Catarina, Flavinho manteve-se esperançoso e vigilante, acessou as plataformas de informações oficiais sobre o trânsito entre Brasil e Alemanha em busca de brechas ou alterações nas regras de embarque. Seria possível que no decorrer dos dias estas se afrouxassem, ou mesmo, que os casos de Covid no Brasil diminuíssem? Flavinho não dormia, não comia, seus pensamentos giravam obsessivamente em torno dessas questões e das (falsas) esperanças que construía.

Com o passar dos dias, outros planos foram elaborados. Remarcar as passagens e tentar entrar na Alemanha por outro país, como Itália, Portugal ou Espanha. Mais uma vez, Flavinho entrou em contato com amigos que tinham conseguido por estes meios. Novamente, suas pesquisas e esforços foram em vão. Não era possível mudar as passagens, muitas regras dos países alteravam-se diariamente, assim como as de companhias aéreas.

4 Disponível em: <https://brasil.diplo.de/br-pt/coronavirus/2320108>. Acesso em: 04.01.2021. 
Destemidos e com o firme propósito de realizarem seu plano, uma vez que já não havia mais emprego no Brasil e se viam sem alternativas, Flavinho e esposa resolveram viajar. Entendiam que, caso houvesse alguma restrição, seriam informados no aeroporto ainda em solo brasileiro e, ao apresentarem seus documentos italianos, o problema estaria resolvido. O casal embarcou em Florianópolis rumo a São Paulo, de onde seguiriam até o destino final Frankfurt.

Recebemos uma ligação no dia da viagem. Acreditamos que Flavinho ligava para se despedir e contar que estava finalmente embarcando para a Alemanha, porém o tom do telefonema era outro. O casal foi barrado no guichê do aeroporto em Guarulhos e orientado a retornar à Santa Catarina e remarcar o voo internacional em outra oportunidade. $\mathrm{O}$ argumento fornecido pela companhia aérea indicava a grande probabilidade da entrada do casal na Alemanha ser negada, levando-os a ser deportados, o que gerou grande receio e ansiedade em Flavinho. A dúvida ainda residia no fato de o casal ter podido embarcar em Florianópolis rumo a São Paulo, de onde sairia o voo internacional. Com o embarque em Florianópolis, Flavinho achou que corria tudo bem. Como os funcionários de uma mesma empresa aérea teriam informações tão díspares?

Por fim, o casal aguardou um telefonema com representantes da companhia aérea em Frankfurt, no qual, explicaria que tinha posse do documento italiano e um contrato de trabalho na Alemanha. Porém, a espera foi em vão, Flavinho e sua esposa não entrariam no país, mesmo munidos desses papéis. Exaustos após o longo dia de viagem, não conseguiram lugares em um voo de volta à Santa Catarina. Permaneceriam no aeroporto até o dia seguinte, pois com as muitas malas e o cansaço, também não conseguiriam chegar a rodoviária em São Paulo para embarcar em um ônibus que rodaria cerca de 15 horas até sua cidade. Era a vivência de um paradoxo: possuir todos os documentos, comprovantes, trabalho certo, moradia e mesmo assim não poder se mover.

\section{Considerações finais}

Este relato da vida real revela algumas questões que perpassam a crise gerada pela pandemia do novo coronavírus. No caso dos ítalo-brasileiros que acompanhamos, o modo como se constituiu sua (i)mobilidade se apresentou como um fato novo. A pandemia levou-os a uma paralização, não somente em termos do ir e vir, mas também quanto ao futuro de seu movimento migratório e, por consequência, o futuro do andamento das construções de suas casas, do sustento de suas famílias e da organização comercial e turística de seu município como um todo.

As dúvidas quanto ao prosseguimento da disseminação do vírus e também a incerteza sobre a continuidade de suas idas e vindas para a Alemanha revelam-se grande fonte de preocupação. Em uma região em que tudo gira em torno da circularidade e continuidade do movimento migratório dos ítalo-brasileiros, 
não há vislumbre de uma saída a curto prazo. Mesmo que o almejado retorno dos migrantes não se estabeleça conforme esperado em seus projetos iniciais, acredita-se, mesmo assim, em um modo de vida que "dá certo" - o modo de vida em trânsito, que mantém as esperanças de ascensão social e econômica pelo trabalho nas sorveterias.

No caso daqueles que viviam na esperança da consolidação de seu retorno definitivo, para finalmente habitarem seus lares no Brasil, e permanecerem em casa, as condições impostas pelo coronavírus instauram uma ironia da imobilidade. Além de irônica, esta imobilidade denuncia que seus passaportes não mais os legitimam como cidadãos com livre entrada e circulação na Europa. Faz-se necessária a construção de estratégias para lidar com as novas dificuldades de trânsito daqueles tão acostumados ao ir e vir permanente, irrestrito. A pandemia lhes apresentou seu não lugar, mesmo com todas as prerrogativas para que a situação fosse o contrário. A frustração de viverem o não planejado vai além da imobilidade representada pelo não deslocamento, mas pela complexidade de sua esfera social e política.

\section{Referências bibliográficas}

CIAMPA, Antônio da Costa. Políticas de identidade e identidades políticas. In: DUNKER, Christian Ingo Lenz; PASSOS, Maria Consuelo (orgs.). Uma psicologia que se interroga: ensaios. São Paulo: Edicon, 2002, p. 133-144.

COSTA, Jamile dos Santos Pereira; ZANINI, Maria Catarina Chitolina. O reconhecimento da cidadania italiana como fato, valor e processo: o passaporte como símbolo de italianidade. REMHU, Revista Interdisciplinar da Mobilidade Humana, Brasília, v. 27, n. 55, p. 165-180, 2019.

PORTUGUEIS, Diane. "Lá e cá" histórias e projetos de vida de sorveteiros ítalobrasileiros na Alemanha: ensaio e apontamentos de pesquisa. Cadernos Obmigra, v. 2, n. 1, p. 38-59, 2016.

PORTUGUEIS, Diane. Vidas em trânsito: ascensão financeira e o enredo identitário que aprisiona na condição liminar. Sorveteiros ítalo-brasileiros entre Itália, Alemanha e Brasil como (não) lugares. Tese de doutorado. Pontifícia Universidade Católica de São Paulo, Instituto de Psicologia Social, São Paulo, 2018.

PORTUGUEIS, Diane. O amargo sabor do sorvete: interrupção de projetos de vida de sorveteiros ítalo-brasileiros na Alemanha em tempos de COVID-19. In: GROSSI, Miriam Pillar; TONIOL, Rodrigo (orgs.). Cientistas Sociais e o coronavírus. São Paulo/ Florianópolis: ANPOCS/Tribo da Ilha, 2020a, p. 238-241.

PORTUGUEIS, Diane. Rearranjos e trajetórias: ítalo-brasileiros trabalhadores em sorveterias na Alemanha em tempos de Covid-19. In: Anais do III Encontro Nacional do Núcleo de Pesquisa Dialética Exclusão/Inclusão Social NEXIN, São Paulo, 29 de outubro a 03 de novembro de 2020b.

TURNER, Victor Witter. O processo ritual. Estrutura e antiestrutura. Petrópolis: Vozes, 2013 [1969]. 